\title{
MICROSTRUCTURE EVOLUTION OF Ni-BASED ODS SUPERALLOY POWDERS DURING HORIZONTAL ROTARY BALL MILLING
}

\begin{abstract}
Microstructure evolution of Ni-based oxide dispersion-strengthened alloy powders with milling time is investigated. The elemental powders having a nominal composition of Ni-15Cr-4.5Al-4W-2.5Ti-2Mo-2Ta- $0.15 \mathrm{Zr}-1.1 \mathrm{Y}_{2} \mathrm{O}_{3}$ in wt \% were ball-milled by using horizontal rotary ball milling with the change of milling velocity. Microstructure observation revealed that large aggregates were formed in the early stages of ball milling, and further milling to $5 \mathrm{~h}$ decreased particle size. The average crystalline size, estimated by the peak broadening of XRD, decreased from $28 \mathrm{~nm}$ to $15 \mathrm{~nm}$ with increasing milling time from $1 \mathrm{~h}$ to $5 \mathrm{~h}$. SEM and EPMA analysis showed that the main elements of $\mathrm{Ni}$ and $\mathrm{Cr}$ were homogeneously distributed inside the powders after ball milling of $5 \mathrm{~h}$.

Keywords: Ni-base ODS superalloy, High energy ball milling, Particle and crystalline size, Microstructure
\end{abstract}

\section{Introduction}

Ni-base oxide dispersion strengthened (ODS) superalloys are widely used in aircraft and advanced gas turbine engines due to their excellent mechanical property and environmental resistance at high temperature [1-3]. For example, conventional ODS superalloys such as MA 6000 and PM 3030 [4,5] show excellent creep resistance by combination of gamma prime precipitation strengthening at intermediate temperature and dispersion strengthening at high temperature. These ODS alloys are usually manufactured by mechanical alloying (MA), in which the elemental metal and oxide powders are subjected to the high-energy ball milling to allow the nano-sized oxide particles to be homogeneously dispersed in alloy matrix powders [6]. After MA processing, the alloyed powders with oxide particles are consolidated by hot isostatic pressing or hot extrusion. However, this complicated fabrication process has caused a difficulty in exact control of microstructure and properties $[7,8]$. Nevertheless, the morphology and structural change of the ODS superalloy powders during high-energy ball milling has not been comprehensively reported. Therefore, the effect of milling condition on the microstructure evolution is investigated for MA6000 powder having a nominal composition of Ni-15Cr-4.5Al-4W-2.5 Ti-2Mo-2 Ta-0.15Zr-1.1 $\mathrm{Y}_{2} \mathrm{O}_{3}$ in wt \%.

\section{Experimental}

Experimental composition and characteristics of staring powders used in this investigation are listed in Table 1. The starting powders were initially mixed in a tubular mixer for $1 \mathrm{~h}$. Fig. 1 shows the typical SEM image of the mixed powders. Then, the powder mixture together with stainless steel balls was sealed under an Ar gas in vessel. The high-energy milling was carried out for 1 to $5 \mathrm{~h}$ using horizontal ball milling machine (Simoloyer, Zoz GmbH, Germany) with a ball-to-powder weight ratio of 15:1. To improve the milling efficiency [9], the milling velocity was periodically changed as cyclic operation with a time interval of $4 \mathrm{~min}$ at $1200 \mathrm{rpm}$ followed by $1 \mathrm{~min}$ of operation of $900 \mathrm{rpm}$.

TABLE 1

Experimental composition (wt \%), particle size $(\mu \mathrm{m})$ and purity $(\%)$ used in this investigation

\begin{tabular}{|c|c|c|c|c|c|c|c|c|c|}
\hline \hline & $\mathbf{N i}$ & $\mathbf{C r}$ & $\mathbf{A l}$ & $\mathbf{W}$ & $\mathbf{T i}$ & $\mathbf{M o}$ & $\mathbf{T a}$ & $\mathbf{Z r}$ & $\mathbf{Y}_{2} \mathbf{O}_{3}$ \\
\hline $\begin{array}{c}\text { Compo- } \\
\text { sition }\end{array}$ & Bal. & 15 & 4.5 & 4 & 2.5 & 2 & 2 & 0.15 & 1.1 \\
\hline $\begin{array}{c}\text { Particle } \\
\text { size }\end{array}$ & 8 & 28 & 18 & 12 & 26 & $3 \sim 10$ & 2 & $2 \sim 15$ & 0.05 \\
\hline Purity & 99.8 & 99.0 & 99.5 & 99.9 & 99.5 & 99.9 & 99.9 & 99.0 & 99.9 \\
\hline
\end{tabular}

The processed powders were characterized by X-ray diffraction (XRD, D/Max-IIIC, Rigaku Denki Co., Japan) analysis.

\footnotetext{
* DEPARTMENT OF MATERIALS SCIENCE AND ENGINEERING, SEOUL NATIONAL UNIVERSITY OF SCIENCE AND TECHNOLOGY, SEOUL 01811, REPUBLIC OF KOREA

** KOREA SINTERED METAL CO. LTD., DAEGU 42983, REPUBLIC OF KOREA

\# Corresponding author: stoh@seoultech.ac.kr
} 
1254

The microstructure and elemental mapping were observed by scanning electron microscopy (SEM, JSM-6700F, JEOL Co., Japan) equipped with an electron probe micro-analyzer (EPMA). The particle sizes were estimated from the measurements of above 50 powders which were selected from SEM micrographs of ball-milled powders.

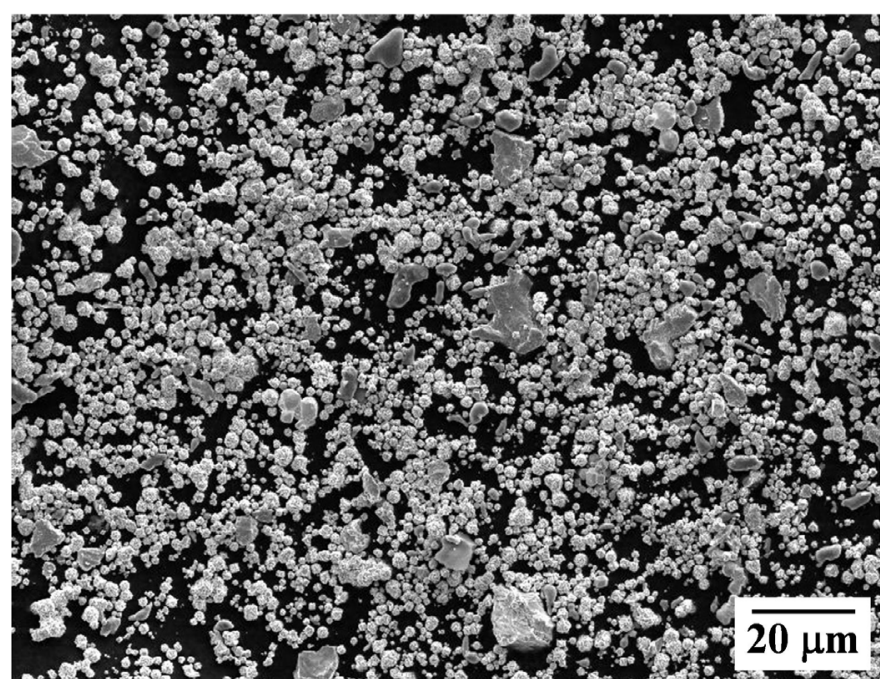

Fig. 1. SEM image of mixed powders in a tubular mixer for $1 \mathrm{~h}$

\section{Results and discussion}

The morphology of powder mixtures produced at different milling times was observed by SEM. As shown in Fig. 2a-d, the early stages of mechanical alloying $(1 \mathrm{~h}$ and $2 \mathrm{~h}$ ) result in the formation of powder aggregates having a wide range in size. In this stage, the particles are crushed down and cold weld together to form even larger particles. Further milling leads to increased deformation and work hardening [7,10], and thus large aggregates disintegrate into fragments producing finer particles as shown in Fig 2d.
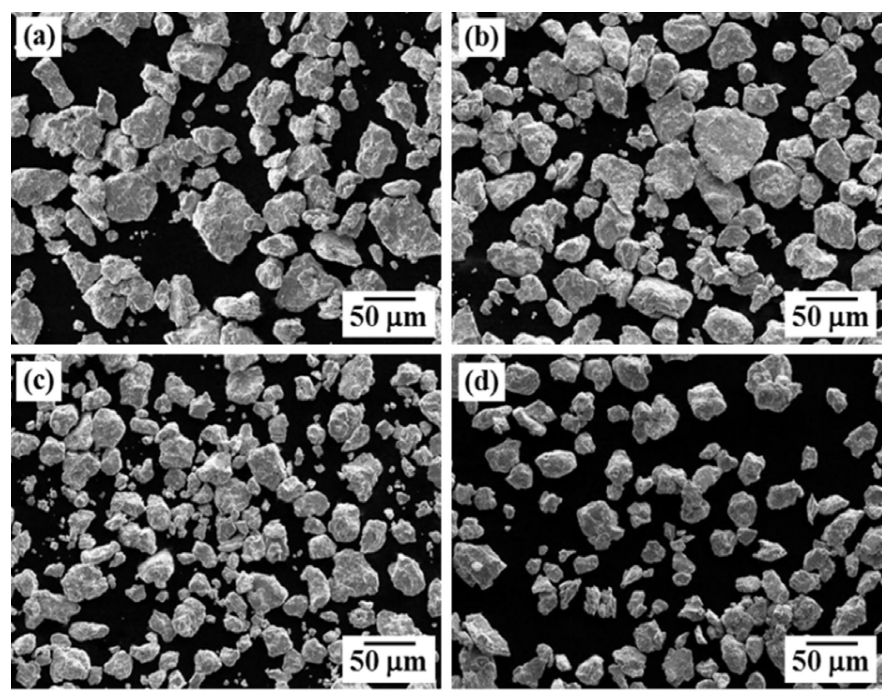

Fig. 2. SEM micrographs of the powder mixtures obtained after high energy ball milling for (a) $1 \mathrm{~h}$, (b) $2 \mathrm{~h}$, (c) $3 \mathrm{~h}$ and (d) $5 \mathrm{~h}$
The XRD patterns of the ball-milled powder mixtures with various milling times are shown in Fig. 3. The pattern of ballmilled mixture for $1 \mathrm{~h}$ shows the peaks of all major alloying elements such as $\mathrm{Ni}, \mathrm{Cr}, \mathrm{Al}$ and $\mathrm{W}$. With increasing the milling time to $5 \mathrm{~h}$, the intensity of the diffraction peaks decreases and the width of the peaks increases. The peak broadening indicates that the crystalline size decreases with increase in milling time. In this regard, the crystalline sizes of the ball-milled powders under different milling times have been calculated through the Hall-Williamson equation [11] with the full-width at half maximum (FWHM) values of the XRD patterns.

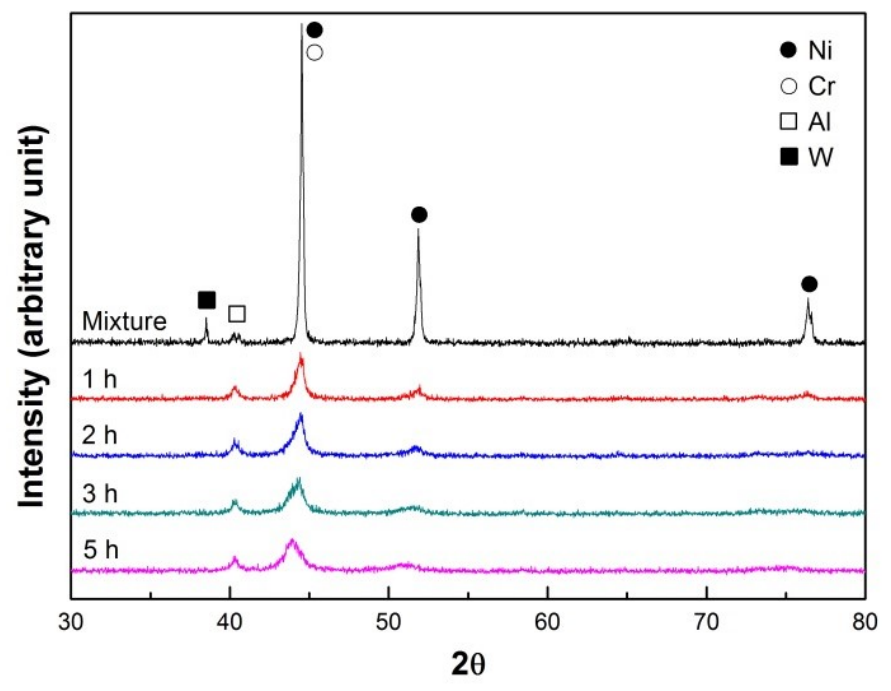

Fig. 3. XRD patterns of powder mixtures mechanically milled for 1 , 2,3 and $5 \mathrm{~h}$

Fig. 4 shows the variations of particle and crystalline sizes during milling, which were obtained by measurement from SEM images of Fig. 2 and Hall-Williamson equation, respectively. The variation of average particles size seems to be typical high-energy milling process. As explained in Fig. 2, increase in particle size at the beginning of milling operation is resulted from repeated

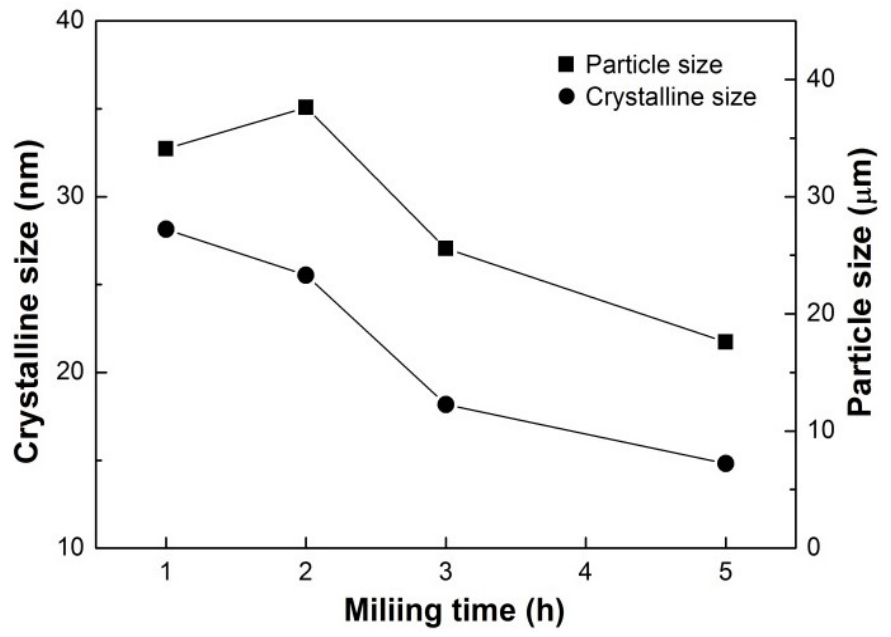

Fig. 4. The variations of average particle and crystalline sizes versus milling time 
welding of particles. After milling time of $5 \mathrm{~h}$, the aggregates size decreased to $17.5 \mu \mathrm{m}$ by disintegration of severely deformed powders. Also, it is shown in Fig. 4 that the crystalline size decreases from $28 \mathrm{~nm}$ to $15 \mathrm{~nm}$ with increasing milling time from $1 \mathrm{~h}$ to $5 \mathrm{~h}$. Thus, it is suggested that fine powder with nano-sized crystalline can be fabricated by the cyclic operation with less milling time compared with conventional milling $[9,12]$.

In order to characterize the microstructure, SEM-EPMA analysis of the powder ball-milled for $5 \mathrm{~h}$ was performed. As clearly seen in Fig. 5, the aggregates constituted of many small grains are observed. Also, the phase of ball-milled powders as determined by EPMA mapping is presented in Fig. 5, in which main elements ( $\mathrm{Ni}$ and $\mathrm{Cr}$ ) are distributed evenly in the powders.
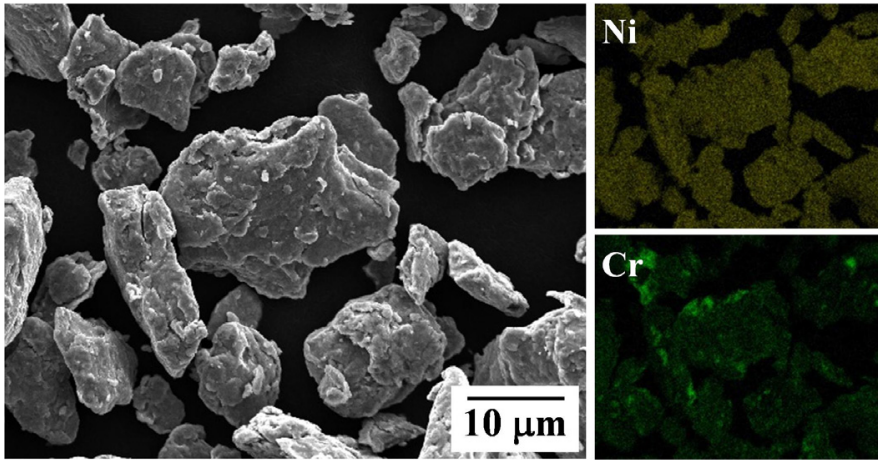

Fig. 5. SEM image and related EPMA maps of mechanically milled MA6000 alloy powder

\section{Conclusions}

This work has demonstrated the microstructure evolution of Ni-based ODS superalloy powders during horizontal rotary ball milling. Starting powders with composition of MA6000 alloy were initially mixed in a tubular mixer and ball-milled by cyclic operation with periodically changed milling velocity. $\mathrm{XRD}$ analysis revealed that the intensity of the diffraction peaks decreases and the width of the peaks increases with increasing the milling time. In the early stages of ball milling, the formation of large aggregates was observed. Further milling to $5 \mathrm{~h}$ leads to the disintegration of aggregates into fragments producing finer particles. The crystalline size decreases from $28 \mathrm{~nm}$ to $15 \mathrm{~nm}$ with increasing milling time from $1 \mathrm{~h}$ to $5 \mathrm{~h}$. SEM and EPMA analysis showed that the main elements of $\mathrm{Ni}$ and $\mathrm{Cr}$ were homogeneously distributed in ball-milled powders. These results indicated that fine and homogeneous alloy powders can be successfully fabricated by the horizontal rotary ball milling with cyclic velocity operation.

\section{Acknowledgments}

This work was supported by the Technology Innovation Program (10048158, Development of $980^{\circ} \mathrm{C}$ grade superalloys strengthened by multi-component nano-oxides for commercialization of core materials in the field of the defense industry) funded by the Ministry of Trade, Industry and Energy (MI, Korea).

\section{REFERENCES}

[1] W. Betteridge, S.W.K. Shaw, Mater. Sci. Technol. 3, 682-694 (1987).

[2] D. Furrer, H. Fecht, JOM 51, 14-17 (1999).

[3] T.M. Pollock, S. Tin, J. Propul. Power 22, 361-374 (2006).

[4] S.K. Kang, R.C. Benn, Metall. Trans. A 18, 747-752 (1987).

[5] M. Nganbe, M. Heilmaier, Int. J. Plast. 25, 822-837 (2009).

[6] J.S. Benjamin, Metall. Trans. 1, 2943-2951 (1970).

[7] C. Suryanarayana, Prog. Mater. Sci. 46, 1-184 (2001).

[8] L. Ma, B.S.-J. Kang, M.A. Alvin, C.C. Huang, KONA Powder Part. J. 31, 146-155 (2014)

[9] Y.D. Kim, J.Y. Chung, J. Kim, H. Jeon, Mater. Sci. Eng. A291, 17-21 (2000).

[10] D. Maurice, T.H. Courtney, Metall. Mater. Trans. A 25, 147-158 (1994).

[11] B.D. Cullity, Elements of X-Ray Diffraction, 2nd Ed., New York 1978.

[12] C. Capdevila, H.K.D.H. Bhadeshia, Adv. Eng. Mater. 3, 647-656 (2001). 